\title{
Algorithmic Bureaucracy
}

\section{Managing Competence, Complexity, and Problem Solving in the Age of Artificial Intelligence}

\author{
Thomas M. Vogl \\ Oxford Internet Institute \\ University of Oxford \\ Oxford, United \\ Kingdom \\ thomas.vogl@oii.ox.ac. \\ uk
}

\author{
Bharath Ganesh \\ Oxford Internet Institute \\ University of Oxford \\ Oxford, United \\ Kingdom \\ bharath.ganesh@oii.ox. \\ ac.uk
}

\author{
Jonathan Bright \\ Oxford Internet Institute \\ University of Oxford \\ Oxford, United \\ Kingdom \\ jonathan.bright@oii.ox. \\ ac.uk
}

\begin{abstract}
In recent years, local government is undergoing changes which are strongly influenced by the growing digitization of governmental operations. Key features of Digital Era Governance (DEG) appear to be displacing features of the New Public Management (NPM) and are also challenging some underlying aspects of Weberian bureaucracy in public administration. In this paper, we expand on the concepts in DEG and its successor, Essentially Digital Government (EDGE), by introducing the concept of Algorithmic Bureaucracy, which looks at the impacts of Artificial Intelligence (AI) on rationalization and the socio-technical nature of public administration. We report on a mixed-method study, which focused on how the growth of data science is changing the ways that local government works in the UK. Special emphasis is put on how algorithms can build citizen and administrator competence and deal with complexity. Algorithmic bureaucracy, like traditional bureaucracy, is impartial in its application, but can be predictably sensitive to context. Society needs to determine the ends to which it is put and how to assign accountability in this context. We find that algorithmic bureaucracy is in its infancy in local government, so there is space to develop an appropriate ethical framework to harness the technology and enhance social problem solving.
\end{abstract}

\section{KEYWORDS}

Algorithmic Bureaucracy, Digital Era Governance, Local Government, Socio-technical systems, Data Science

\section{Introduction}

The work of local government in the UK is in a period of transition. Years of New Public Management reforms have fragmented services and put providers at odds with one another. It has led to duplicated administrations and imposed limited performance metrics based on siloed data. These changes were built on top of a foundation of Weberian bureaucracy where vestiges of hierarchy, procedures, and public sector socialization persist [13]. However, in the last ten years, wholesale digitisation has created new tools for front office service interactions, and allowed more citizens to make a digital 'channel shift' with their local municipality $[13,31]$.
This increased digitisation of government operations has generated a wealth of administrative data on citizen preferences and behaviours, which are analysed more effectively than ever before. New sources of data, such as data from IoT devices, social media and mobile phones are emerging [42]. At the same time, new analytical techniques have improved our ability to understand this data and use it (for example, the rise of predictive analytics, artificial intelligence and $\mathrm{A} / \mathrm{B}$ testing) [39]. Finally, these new techniques are supported by developments in the tools available (for example, sophisticated, open source software, such as R and Python) which enable machine learning at low cost to those who have the necessary skills. These three overall changes challenges old ways of working and raises the possibility of new approaches to organizing in public administration.

We introduce the concept of 'Algorithmic Bureaucracy' to encapsulate these three elements of change, which together offers a novel take on current conceptualizations of public administration and produces ways to overcome challenges often associated with changes in public management regimes, including competence and complexity. We build on DEG and EDGE concepts (see section 2) by emphasizing the relationship between citizens and professional public servants when mediated by technology. Moreover, while abandoning some aspects of traditional Weberian bureaucracy, which will be discussed below, we draw on the concept of organisation as a socio-technical system and rationalization to enhance problem solving despite changes in public administration [13].

In this paper, we explore how digitized data and the application of algorithms can 1) deal with greater rule complexity; and 2) enhance citizens' and public administrators' autonomy and competence all in service of improving social problem solving. We explore how these factors can allow for greater equality of outcomes through 
procedurally fair means of processing data; and 3) improve human record keeping and decision making by overcoming issues related to relevance and bounded rationality or limitations in the information processing capabilities of people. We do so by presenting a study in which we analysed 'data science' in local government in the United Kingdom (UK). This mixed-method study builds on a survey and semi-structured interviews with people working in the area of local government 'data science' in the UK.

What will now follow is a brief description of the theoretical background, which focuses on the development of public administration in order to contextualize our work in local government. Then, we elaborate on our applied methods and analysis. Afterwards, we present our findings, where we look at five examples of barriers from previous forms of administrations and five examples of local authorities overcoming barriers to implement DEG and EDGE changes. Then, we explore two broader socio-technical and rational features that influence the impact of Algorithmic Bureaucracy on public management change and social problem solving. The paper ends with a conclusion on the role 'Algorithmic Bureaucracy' can take in enhancing citizen and administrator autonomy and competence and organizational ability to deal with institutional and policy complexity.

\section{Background}

In this section, we briefly touch upon the development of Public Administration in order to contextualize how Algorithmic Bureaucracy can enhance competence and deal with complexity more effectively than previous public administration paradigms.

\subsection{Progressive Public Administration}

Government organizations in the UK have been shaped by trends in public administration reform. Local authorities are no exception. One can find a palimpsest of different approaches in tenuous coexistence. During the progressive era of public administration in the late nineteenth and early twentieth centuries, progressive public administration (PPA), characterized by hierarchy, impartiality through procedural rules, and public sector ethos, built on Weberian principles [47]. Some of these characteristics can still be seen today in the internal rules and procedures for administration of local authorities. One of Weber's key insights was that bureaucracy was valuable because it increased calculability [47]. Through the technology of writing, administrators could pass on rules and official information over time, creating a sense of predictability in the organization. Whereas before, partial decision making could make interaction with the state unpredictable, we moved into a situation where everyone would know the procedures to which they would be subject. Today, writing is machine readable and computers over internet protocols can transfer and process information in real-time. In this context, it is possible to respond to contextual differences in predictable ways to process greater complexity, deal with limitations in human information processing, and solve social problems. Undue focus on hierarchy and procedure can limit moves towards bottom-up and outcomes based digital change [13]. That being said, some of Weber's ideas about socio-technical systems and rationalization in public administration resonate today.

\subsection{New Public Management}

The NPM is characterized by disaggregation, competition, and incentivization and was a predominant paradigm of public administration in the UK in the 1980s and 1990s. It had particularly large impacts on local authorities, as it was associated with devolution to the level of government closest to citizens, fragmentation of services, and greater performance measurement for professional decision making. Some of these changes would pull apart hierarchy and deprofessionalize organizations in favor of incentives from performance measures. Not only did the NPM shift focus to disaggregation and competitive performance, but it downplayed how expertise is institutionalized in people and technology $[1,12]$, ultimately making the public sector ill equipped to harness the opportunities made possible by the digital age.

\subsection{The end of New Public Management}

More recently, researchers have argued that the NPM has met its end [12] and that a DEG approach to public administration characterized by reintegration, digitization and needs-based holism is resulting from the growth of networked information technologies and the internet [11, 32].

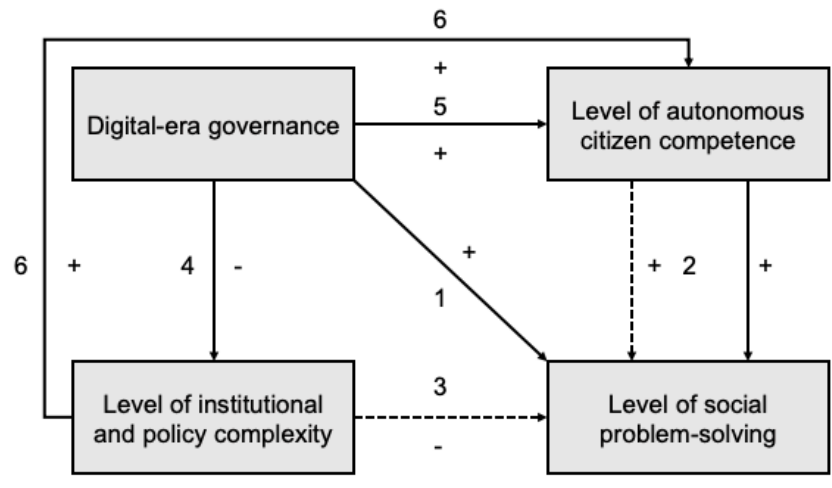

Figure 1. DEG and social problem solving. Adapted from [11] 
DEG was seen to have a net positive impact on social problem-solving relative to NPM. Figure 1, above, illustrates not only the direct impact of Digital-era governance (DEG) on the level of social problem-solving (flow 1), but also the numerous indirect effects (flows 4-6) and direct effects from other sources (2-3). Flow 2 illustrates that autonomous citizen competence can have both a direct (solid line) and indirect (dotted line) increase on the level of social problem-solving. Flow 3 illustrates that the level of institutional and policy complexity can have an indirect negative impact on the level of social problem-solving. Flow 4 illustrates that DEG changes have a direct effect on decreasing the level of institutional and policy complexity (through reintegration), which in turn has a direct effect on increasing the level of autonomous citizen competence (reversals from the impacts of the earlier NPM). Finally, flow 5 illustrates that DEG has a positive influence on the level of autonomous citizen competence (through disintermediation resulting online services).

Recently there has been a shift from DEG to EDGE, which puts technology at the centre of government and which looks at what DEG can enable, including equality of outcomes, an organizational structure characterized by an intelligent center and devolved delivery, and isocratic service delivery (where individuals serve themselves online) [10]. While many of the features of DEG and EDGE are visible in local government, there are also elements around rationalization and the structure of the socio-technical system that are not captured under these paradigms. We argue that it is relevant to explore these two additional features as they influence the impact of Algorithmic Bureaucracy on dealing with competence and complexity in social problem solving. We elaborate on the relevance of considering these features in section 4.2 .

\section{Methodology}

This research builds on empirical material, which was collected as a part of the Data Science for Local Government project. This project aimed to understand how the growth of 'data science' is changing the way that local government works in the UK. This section elaborates on the applied methods and the analysis.

Our study is based on research that took place between November 2017 and December 2018. It reports on desk research, survey responses, and subsequent in-depth interviews conducted with people working in the area of local government "data science" in the United Kingdom (UK). Personal email invitations to complete the survey were sent to at least one person in all of the (almost 450) local authorities in the UK. The survey was at least partially completed ( $29 \%$ or more of the survey was completed) by 118 respondents. Based on respondents who volunteered their local authority, at least 64 different local authorities were represented. Semi-structured interviews were conducted with individuals who were selected based on their survey responses or their online profile found during the earlier search and who were either working in UK local authorities or in enterprises providing data science services to these authorities. Of those contacted, 34 were interviewed by phone or over Skype. The limitations are that we could not control who responded to the survey and that the individuals involved responded in a personal capacity. As a result, the findings from the survey and interview should be considered indicative rather than conclusive.

The data was conducted and analyzed in three main steps. First, desk research was conducted as a means to identify people working with data science and analytics in local government. Then, we conducted the survey on which basis we produced descriptive statistics. Finally, the survey results informed the structure of the following in-depth interviews. The interviews were all audio recorded. We collectively reviewed interview recordings in order to identify key themes and quotes, which were noted or transcribed. These three steps - desk research, survey results, and interview responses - were used to triangulate common themes and form nuanced understandings.

\section{Findings}

Local authorities were particularly hard hit by NPM and were seen as low achievers in the area of IT development and implementation [11]. If local authorities are starting to implement IT projects, this is a good indication that there is a shift from NPM to DEG [32]. In presenting the findings of this study, we first elaborate on five identified challenges to digital changes in local authorities, as well as examples of how local authorities overcome these barriers to implement DEG and EDGE changes. Then, we review different examples of AI currently being used in local government in the UK, which illustrate shifts towards DEG and EDGE changes.

\subsection{The administrative lineage of challenges to digital changes in local authorities}

This section presents five challenges to digital changes in local authorities. These challenges represent features of past administrative systems that persist today, and which all interfere with the progress of Algorithmic Bureaucracy. 
The first challenge constitutes the fundamental need to 'make the case' to senior management in order to get them to buy in and allocate time to data science projects in local government. Staff still need to seek approvals up the hierarchy to move projects forward. In our survey research respondents referred to a lack of commitment to developing a culture that fosters the use of data analytics in creative ways. One interviewee said that "part of my job is to bridge the gap between the technology and the leadership because it is all too easy for technology to end up in the corner, gathering dust, and never getting used. Getting leadership buy in is a huge challenge with this type of work" (Skype interview, third quarter, 2018). Based on our empirical data, we find that the most effective way to make the case is when staff combine case studies and initial analysis from the ground level which demonstrates some tangible benefits. For example, one interviewee said that "if you show real benefit and value to people of using those insights, you're much more likely to get that kind of buy-in that you need to make that step to becoming a data-driven organization" (Phone interview, third quarter, 2018). New digital tools are allowing front-line staff to try things and brief up. This helps to reverse hierarchical top-down information flows.

The second challenge revolves around procedural rules and information processing. Targeted inspections offer another case. A variety of different branches of local government need to enforce local rules. For example, authorities need to make sure that council tax is paid correctly or to find Houses of Multiple Occupation (HMOs). Inspections are a key element of enforcement and they depend on an inspector's ability to process and use information. One potential use of predictive analytics is to improve the efficiency of inspection operations. Belfast contracted a company called Analytics Engines to develop a tool to more accurately identify properties paying incorrect business rates. The software improved the efficiency of inspection teams by more than $200 \%$ and found almost $£ 400,000$ of unclaimed rates in just the first weeks of operation [2]. Here predictive analytics helped to overcome the limitations individuals or teams may face when applying standard procedures, professional discretion, and heuristics to information processing, by taking the unique features of each case into account, while attempting to achieve the same outcome.

Competition and procurement represent the third challenge for local authorities. NPM and its focus on competition reduced internal IT capacity both for development, maintenance, and procurement. Thus, government may lack key skills and knowledge during the procurement process, though the situation may be improving. As one interviewee commented: "I hope we are moving towards a moment when government agencies are intelligent buyers and users of this technology" (Phone interview, third quarter, 2018). Despite limited resources and capacity, local authorities are overcoming these barriers by purchasing off the shelf solutions or by learning how to acquire and use open source software. The majority of our interviewees had chosen to engage with off-the-shelf software solutions such as Power BI, ESRI, Tableau and Liquidlogic. Several of the interviewees expressed how these types of software have been valuable tools to support a growing trust in the data, which has further induced organisational changes. There was also a small but significant group of people making use of open source packages such as R \& Python (26\% of survey respondents).

The fourth identified challenge points out the need to overcome the NPM focus on short-sighted performance measures that do not depend on complex analytics because they are leading to short-term and potentially sub-optimal long-term decision making. Several of our interviewees addressed the significant financial cutbacks in recent years in local government administrations and emphasized the negative impact budget saving and statutory requirement incentives have on decision makers. Many of these cutbacks have fallen on non-frontline staff, which can often mean people with analytical skills. One interviewee expresses how the ability to make use of data in new and valuable ways are highly dependent on the people: “... while some of the materials are recorded, the actual knowledge capital of interpretation and context could be lost, and you have to start from scratch, even when the data is there. So, the question is how do you build on these pieces of work" (Phone interview, third quarter, 2018). This indicates that while a desire to preserve frontline staff is understandable, these cuts may have been counterproductive in the long term. Senior management performance incentives and performance measurement stemming from the New Public Management may be leading to short term decision making with long term negative impacts. However, our study shows examples of local authorities overcoming this barrier by carving out time to show management the value of the analytical skills.

Finally, the fifth challenge touches upon fragmentation and data sharing. The ability to share data (between different branches of an agency, between different agencies within a local authority and even between local authorities) is a fundamental enabler of some information processing with $\mathrm{AI}$; it is also one of the most difficult challenges for local authorities to overcome. In our survey, $53 \%$ of the respondents reported that difficulties with 'data silos' were the most frequently mentioned barrier to data science projects. The ability to share data can be further complicated 
by the fact that the work takes place in fragmentated markets with multiple suppliers, who often have incompatible systems. One interviewee highlighted this challenge by using an example from her own work: "...we use eleven different systems, none which talk to each other, and most of which don't use the same unique identifier. We were getting increasingly frustrated that we thought there was value in the data, but we couldn't make people understand that value, because they can't physically see the information, because it's all hidden in these systems" (Phone interview, third quarter, 2018). Our data shows that some local authorities are making slow progress to move beyond these data sharing issues. One interviewee shares an example where the interviewee's lab developed a data model that aimed to speed up the discharge process in NHS Scotland. However, the process of developing and testing this model in fragmented market with multiple stakeholders took more than a year. This exemplifies one impact of the complexity of sharing data, which is that, while it can be achieved, the barriers can dramatically slow down development cycles (Phone interview, third quarter, 2018).

Together, these challenges illustrate how past approaches interfere with novel approaches and how organizations are overcoming these challenges.

\subsection{Artificial Intelligence in the UK}

In this section, we review examples of AI which are currently being used in local government in the UK. Through these examples, we will look at how components of DEG and EDGE are manifesting through the use of data, algorithms, and AI to help alleviate some of these pressures, or to provide a supplement to existing services.

One way that AI is beginning to be applied in local government is through the introduction of predictive analytics and decision support technologies [5]. Based on our empirical data, these technologies are typically computerised systems which aim to support public servants making service intervention decisions. The most predominant manifestations of these types of systems is in the use of machine learning techniques to produce predictions or risk scores for geographic areas or individual cases: 20 of our survey respondents (16\%) reported that their local authority is experimenting with some kind of predictive analytics or decision support [5]. Machine learning involves making use of past service data to derive algorithms that are constantly adapting to new data inputs, and which are used to support the prediction of future outcomes. Rather than being explicitly programmed, parameters of the algorithm are learnt, and the predictions can be used as a decisionmaking aid. Systems such as those provided by machine learning technologies offer an opportunity to move away from procedural equality towards equality of outcomes. One interviewee provided an illustrative example related to strategic forecasting: "We found through our work with various local authorities that one of the areas that they struggle with is special educational needs ... The authority has a big task in trying to figure out what needs are going to arise, in what age children will go to school, where in the area the children will be living, and therefore where they need provision. We built a machine learning model to simulate future demand for places and how that varies if the local authority changes their policy on something, or if other external factors change such as housing ... we help them think through this problem which is just impossible using something like Excel." (Phone interview, third quarter, 2018). This approach not only demonstrates novel uses of data, but illustrates a deeper shift in administrative structure driven by the collection, processing, and presentation of information. This is made possible by digitization, which allows for the continual processing of the stream of data that flows into local authorities through their provision of services.

As an example that can enable the use of applied AI in the context of local authorities, we identified that many councils are investing in 'ETL' (extract, transform and load) software to help automate some complex data connection operations. Some local authorities are considering the use of automatic text processing technologies to simplify the ETL stage of the process. In general, interoperability of datasets was identified as a persistent problem by respondents across all local service sectors ( $53 \%$ of survey respondents). There are a variety of common challenges and issues which recur in projects that require integrated data $[17,18,24,46,50,51]$. One of the key concerns is establishing access to data. Many councils may lack a comprehensive understanding of their data holdings across departments and may have different levels of maturity when it comes to who is responsible for owning and managing them [42]. After getting access to data there can be additional challenges when connecting and merging data which may be held in many different, and potentially incompatible, formats $[16,19,20,26,33,52]$. Another approach to managing data is to design and develop high quality structured data formats, such as relational databases that can be easily queried. One local authority has been working on exposing some non-sensitive types of council information (such as bin collection times) as APIs. This approach requires data to be structured in a usable form and allows other services to be built on top, reducing software dependencies (Phone interview, third quarter, 2018). 
Reintegration can also be interpreted as working across local authorities. One interviewee said: "One of the most promising avenues ... is to work across authorities. This provides the scope for larger trials and potentially enables you to solve problems that single authorities couldn't manage on their own" (Phone interview, fourth quarter, 2018). However, the interviewee also cautioned that working across authorities is by no means straightforward: "things such as different IT systems, differences in the way data is collected and collated and small differences in the way services themselves are delivered all make this type of collaboration a real challenge" (Phone interview, fourth quarter, 2018). This example illustrate how DEG changes in local authorities are beginning to reverse the informational fragmentation caused by NPM to allow for new approaches to data processing.

Another key feature of DEG is Needs-based holism, which involves the reorganization of public services around clients' needs in an attempt to provide an end-to-end service. Again, this was partially in response to the fragmentation of NPM, which put the onus on citizens to navigate the disparate system and coordinate their own services. A holistic approach is aided by digitization insofar as care networks can be coordinated in real time and information can be made available to all relevant parties. For instance, one interviewee shared how they had develop a programme which integrated information from the Fire, Police and Ambulance services to better understand which individuals, households and streets were responsible for the heaviest demand on emergency services [37]. Another interviewee shared how their use of dashboards have been valuable for holistic service that targeted vulnerable people in a local council in $[8,49]$. This programme is based on the automated processing of vulnerable person data to prepare priority lists for emergency planning. The programme links data between 30 providers in health, emergency services, and local authority services under a data governance policy. The system includes a unique patient identifier and an address for GPS mapping, so that the location of the vulnerable individuals can be visualized on a dashboard with an interactive map. These examples illustrate how local authorities are finding ways to provide more holistic services with support from digital technologies.

Once a DEG foundation of digitization, reintegration, and coordination is in place, EDGE activities can be pursued [10]. Some local authorities are beginning to undertake such activities. The concept of an organizational structure with an intelligent centre and devolved delivery depends on the ability of digital technology to at once centralize and decentralize information. Data in the system can be equally used by front-line workers to make local decisions based on individual data, or by senior leaders to make strategic decisions based on aggregate and trend data. Local government has always had a need for forecasting and prediction. However, forecasting has previously largely taken place at a policy or strategic level using aggregate data reported at regular intervals [38]. Our data shows how digital data can bring together the insights of a network of carers to build a collective intelligence that can inform decision making. For example, one interviewee highlighted the particular importance of this type of individualised prediction: "We have been doing some work on risk of homelessness ... the problem is not knowing how many homeless people will there be in general, it's which people will it be, or what pathways will have led them to the stage? That is a more important question ... and this is where machine learning approaches become really useful" (Skype interview, second quarter, 2018). With the processing of administrative data from front line services there is a blurring of the line between what data should be used to inform front line service delivery and what data should be used to inform strategic policy and planning. Often the tools and dashboards at each level are based on the same underlying data. As one interviewee explained: "There is a bit of blurring going on in research and intelligence, between what's performance information and what's business intelligence - who is the customer of data science? The manager or frontline workers?" (Phone interview, third quarter, 2018).

With machine learning techniques, some blunt procedural approaches to individual services can be replaced by more nuanced approaches. To help achieve a positive outcome, these tools may suggest different interventions depending on the context and characteristics of the person in question. These tools can easily process a greater degree of informational complexity than any individual. Emergency services are beginning to explore the potential offered by such analytics. In the context of criminal justice, the United States is using predictive algorithms to inform bail hearings, sentencing and parole decisions $[3,25,29,30]$. In the UK, similar applications are beginning to appear, but they are much more experimental in nature. One example is provided by the Harm Assessment Risk Tool (HART) in Durham. The HART tool provides a risk score for custody officers when processing individuals who have been arrested $[35,43]$. The tool makes use of data on past offending as well as demographic characteristics and divides offenders into low, moderate and high-risk categories. These categories allow custody officers to make different decisions about offenders with different risk levels, for example moderate risk individuals may be eligible for out-of-court rehabilitation 
programmes. The tool can be used to bring more consistent yet contextual decision making to front line workers whether they are new or seasoned veterans. Again, this illustrates a shift from a staff focus on procedures to outcomes, where the human is responsible for the decision and the machine can take on some of the complexity, such as a search of history in previous records and an assessment of risk.

Isocratic administration is an idea where citizens can manage their affairs independently of interactions with government staff by using internet-based platforms to solve their own problems. There are some examples of this approach in local authorities, for example chatbots for routine communication. Chatbots are often part of larger 'channel shift' strategies to get more people making transactions online, except that they can also provide a more interactive way to fill out administrative forms. Some people may prefer this more interactive experience, where they respond to questions and the software populates the form. Chatbots also open the possibility of allowing for simple interactions to be conducted in the language of choice, something which is of increasing relevance for local authorities with international populations. This technology may save resources, but they may also enhance the service, as we saw above with interactive forms, language options, and auditability. In this regard, one interviewee highlighted that citizens seem to appreciate that chatbots (as opposed to telephone or face to face interactions) have the ability to provide an audit trail, which documents that an interaction took place. Chatbots exemplify isocratic service delivery. However, despite the increased level of autonomy made possible by these technologies, there may still be certain cases that the algorithm is unable to address, where the whole service is only partially automated and isocratic, and where a person needs to be involved. The examples above also illustrate the implications of algorithms on our socio-technical understanding of public administration, as well as on key information processing components of rationalization. We elaborate on these aspects in the following section.

\subsection{The influence of socio-technical and rational features}

In this section, we explore two broader socio-technical and rational features, which influence the impact of algorithmic Bureaucracy. One of Weber's key insights was that organizations are socio-technical systems wherein welltrained, qualified, and impersonally selected officials, are brought together in a corporate and systematized organizational configuration, together with the written papers and rules needed to conduct business [13]. Now, it is the interaction of staff in new organizational configurations with electronic information systems that serves to constitute contemporary bureaucracies as socio-technical systems [13]. Local authorities are paying more attention to the interaction between their workers and technology because without highquality record keeping, algorithms might not be effective.

There is a new interaction between machine readable electronic records and those who keep the records. One approach to ensure data quality has been to standardize workflows through the introduction of technology. One interviewee elaborated: "It [the introduction of a new case management system] forces a specific workflow (the order in which tasks have to be completed by a social worker) and that was the biggest change and that was the hardest thing for people to get used to, but it's also the thing that improves data quality, makes the system work, and gives transparency and oversight." (Phone interview, third quarter, 2018). While this higher quality data may improve predictive analytics, service providers are reluctant to use the results for anything more than decision support. All interviewees who commented on predictive analytics were careful to emphasize that these tools should supplement rather than replace existing expert decision making. One interviewee said: "A machine alone cannot make a decision that has legal consequence for an individual ... even the legalities of it aside, I think it's absolutely correct that the human makes the final decision because ... there may be some pieces of a particular case that are very unique to that case which are not reflected by the model ... so we very much view this as a decision aid." (Phone interview, third quarter, 2018). However, predictive analytics and decision support may be changing traditional roles. Another interviewee highlighted that "how our algorithms combine with human judgement and decision-making to get us closer to the 'ideal world' is an open question at the moment." (Skype interview, third quarter, 2018). Here we see the socio-technical system still includes roles for both artificial intelligence and human intelligence, but that the roles may be changing. The use of algorithms may enhance the limited information processing capabilities of humans and allow for increasingly complex rule sets that better determine service needs based on the unique characteristics of each client. The need for written procedures and elaborate information retrieval may decrease as algorithms carry some of this load, allowing workers to focus on their strengths of engaging with clients and providing needed services [6].

Our study includes a number of examples of cases where technological changes are having impacts influencing the behaviour of the socio-technical system. For example, there is also the question of how people who are generating the input data for the tool will respond to its introduction. One interviewee explained that: "it's very important that any kind 
of tool or decision aid that comes about as a result of this work is not used as a performance management tool, or anything to beat social workers about the head with because the moment you do that, then it starts to open the possibility that they will begin to game the predictions ... so the tool itself will not be making effective recommendations because it's being fed information that's designed to trick it." (Phone interview, third quarter, 2018). Focusing on performance management without being cognizant of the socio-technical nature of the system could cause issues because of the risk of perverse incentives $[15,21]$.

The explainability of results is another issue in the context of predictive analytics. Some machine learning techniques are quite obscure, sometimes referred to as 'black boxes' $[34,45]$, and this can make it difficult to discern the precise reasons for decisions. This opacity is seen by some as a threat to transparency and accountability [7, 23, 36]. However, there are techniques that can be more transparent: for example, one data scientist explained how his team has created a prototype tool, which uses structured topic models to point to specific passages in case notes which it uses to support its prediction (Phone interview, third quarter, 2018). The explainability of these tools is important in building trust, but also in trying to deal with bias and in trying to understand why certain decisions are suggested.

Another area of concern is around bias. Both humans and machines can evidence bias, but many people are most concerned about bias in the application of algorithms to decision making areas with sensitive information such as child protection and criminal justice [14, 30, 44]. However, as Cuccaro-Alamin et al. have noted, "Practitioners have difficulty processing large amounts of available information and often used flawed heuristic strategies instead of rational models. Practitioners' personal beliefs and biases and the culture of the agency can also affect assessment" [6]. Further, one respondent said: "I used to say that we don't make predictions about individuals. This is increasingly untenable as a position because of the potential benefits. The moral obligation is to do it but be really careful." (Skype interview, second quarter, 2018). The area where a person lives, or their ethnic or racial characteristics may have a determining impact on the predictions that the algorithm makes and decisions that are made [4]. It may be a critical interaction of human and machine that leads to better results. But, it is not just this interaction that is decisive. Means and ends are also relevant in decision making and in modern societies the means are often driven by rationalization.

Rationalization at its core is the process of moving towards a given end by rational calculation. Rationalization can be based on procedural fairness, equality of outcomes, economics, privacy, public good, or other problem statements. The chosen objective is determinate in the subsequent understanding of what constitutes a rational decision. While there have been critiques of rationalization based on the bounded rationality of people [27, 28, 40, 41], issues in bounded rationality and muddling could be overcome with the complex information processing made possible by AI. With algorithmic bureaucracy, we could be more calculable than ever before, generating predictable results that are sensitive to contextual factors and more nuanced than previous procedural or incentivized decisions. The value of information processing depends on what we are processing information for. If it is primarily for economic reasons, then we may succumb to the 'iron cage' about which Weber warns [48]. But if we set different outcomes then rationalization could lead us successfully towards them.

\section{Discussion}

This paper made three key arguments: 1) the adoption of digital technologies in local authorities raised issues with previous public administration paradigms, such as Progressive Public Administration's Weberian emphasis on hierarchy, procedures, and public sector ethos, as well as the NPM's focus on disaggregation, competition, and incentives; 2) uptake of digital technologies in local authorities supports the public administration paradigms put forward by DEG and EDGE; and 3) the two key Weberian statements about socio-technical systems and rationalization can be given a contemporary interpretation within the context of algorithmic bureaucracy.

With respect to DEG and EDGE changes, not only did we see examples of reintegration, needs-based holism, and digitization, but equality of outcomes, isocratic service delivery, and structures with an intelligent centre and devolved delivery. Intelligent centre, devolved delivery serves both a decentralizing and centralizing function: On the decentralizing side, digitization, linked data, and algorithms can put information from all aligned professionals in the hands of the front-line case worker in real-time. On the centralizing side, these algorithms can equally place information in the hands of those in leadership positions within these organizations, allowing for more informed policy decisions.

The NPM while attempting to add more focus on outcomes through performance measurement handicapped itself by fragmenting service systems, such that data for outcomes measurement was held in different siloes [9, 22]. As we saw in examples above, continued barriers to data sharing from 
fragmentation limit attempts to implement algorithmic systems. DEG served as a response to the NPM through reintegration, needs-based holism, and digitization [12]. Our evidence seems to suggest that DEG changes are continuing. More recently, EDGE appears to be building on the DEG foundation and puts IT at the centre of government organization where the state emerges as a small intelligent core with citizens using a range of digital tools to play a major role in devolved delivery.

Together, these factors are having impacts on the sociotechnical structure of public administration and its means of rationalization. These changes undergird the unique features of Algorithmic Bureaucracy. These can be best understood in the context of Dunleavy et al.'s direct and indirect effects of changes in public management regimes [11]. With Algorithmic Bureaucracy, the polarities in Dunleavy et al.'s mapping of the direct and indirect effects of public administrative changes on the level of social problem solving may reverse in two cases: 1) where through AI and isocratic administration the explainability of algorithmic processes increase citizen and staff competence, and 2) where algorithms take on some of the role of processing institutional and policy complexity much more effectively than humans.

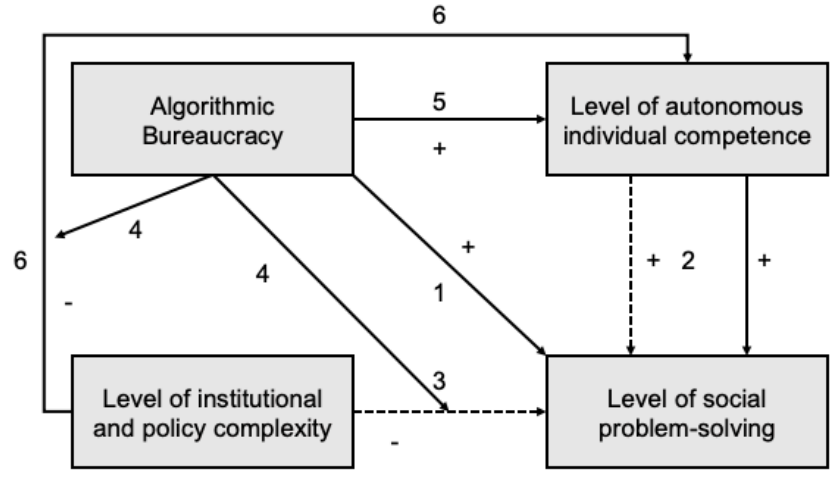

Figure 2: Algorithmic bureaucracy and social problem solving. Adapted from [11]

Figure 2 illustrates not only the direct impact of algorithmic bureaucracy on the level of social problem-solving (flow 1), but also the numerous indirect effects (flows 4-6) and direct effects from other sources (2-3). Flow 2 illustrates that autonomous citizen competence can have both a direct (solid line) and indirect (dotted line) increase on the level of social problem-solving. Flow 3 illustrates that the level of institutional and policy complexity can have an indirect negative impact on the level of social problem-solving. Flow 4, unlike the flow in DEG, understands that the level of institutional and policy complexity may be, to a certain extent, independent from the form of public administration in place. Flow 4 illustrates instead that algorithmic bureaucracy changes (such as AI personal assistants, decision support, and information processing capacities) have a direct effect on mitigating the negative impacts that the level of institutional and policy complexity has on the level of autonomous individual competence (flow 6) and the level of social problem solving (flow 3). Finally, flow 5 illustrates that algorithmic bureaucracy has a positive influence on the level of autonomous individual (not just citizen) competence (through isocratic service delivery, but also through transparency via explainability and decision support technologies for decision-makers and front-line service providers).

Algorithmic Bureaucracy could increase citizen competence through explainability and isocratic administration, and it can handle greater institutional and policy complexity by building rules into code and using algorithms to parse vast sets of data. By altering these two factors it can increase the level of social problem solving by incorporating predictive analytics and decision support. It cannot, however, speak to what society ought to value. Much like a traditional bureaucracy, an algorithmic one can only help with decisions once a public objective is chosen.

\section{Conclusion}

Local authorities face challenges to the introduction of algorithms from elements of traditional forms of public administration, like PPA and NPM. Many local authorities are overcoming those challenges and are implementing projects that align with elements of DEG and EDGE. Once algorithms are introduced, they have unique impacts on the socio-technical systems of public administration. While change in policies and institutions may increase complexity, algorithms may be used to process this complexity such that it does not reduce the level of social problem solving. Further, while algorithms may also be able to directly influence the level of autonomous citizen competence, by building in explainability, they can also help citizens and administrators to understand the growing complexities of contemporary public administration.

\section{ACKNOWLEDGMENTS}

This study was supported by funding from Google. We would also like to thank everyone who took the time to participate in this research.

\section{REFERENCES}

[1] Abbott, A. 1991. The future of professions: Occupation and expertise in the age of organization. Research in the Sociology of Organizations. JAI Press Inc. 1742. 
[2] Belfast City Council Case Study: http://www.analyticsengines.com/casestudies/belfast-city-council-case-study/. Accessed: 2019-01-27.

[3] Berk, R.A., Sorenson, S.B. and Barnes, G. 2016. Forecasting Domestic Violence: A Machine Learning Approach to Help Inform Arraignment Decisions. Journal of Empirical Legal Studies. 13, 1 (2016), 94-115. DOI:https://doi.org/10.1111/jels.12098.

[4] Burgess, M. 2018. UK police are using AI to inform custodial decisions - but it could be discriminating against the poor. Wired $U K$.

[5] Catalyst Project - Improving community services for vulnerable people: https://www.essex.ac.uk/research/showcase/catalyst-project. Accessed: 2019$01-26$.

[6] Cuccaro-Alamin, S., Foust, R., Vaithianathan, R. and Putnam-Hornstein, E. 2017. Risk assessment and decision making in child protective services: Predictive risk modeling in context. Children and Youth Services Review. 79 (Aug. 2017), 291-298. DOI:https://doi.org/10.1016/j.childyouth.2017.06.027.

[7] Danaher, J. 2016. The Threat of Algocracy: Reality, Resistance and Accommodation. Philosophy and Technology. 29, 3 (2016), 245-268. DOI:https://doi.org/10.1007/s13347-015-0211-1.

[8] Datactics Surrey County Council: Vulnerable People Emergency Response Programme. Datactics.

[9] Dunleavy, P. and Hood, C. 1994. From old public administration to new public management. Public money \& management. 14, 3 (1994), 9-16.

[10] Dunleavy, P. and Margetts, H. 2015. Design principles for essentially digita governance. 111th Annual Meeting of the American Political Science Association, 3 - 6 September 2015, American Political Science Association (San Francisco, USA, Sep. 2015).

[11] Dunleavy, P., Margetts, H., Bastow, S. and Tinkler, J. 2006. Digital era governance: IT corporations, the state, and e-government. Oxford University Press.

[12] Dunleavy, P., Margetts, H., Bastow, S. and Tinkler, J. 2006. New Public Management Is Dead - Long Live Digital-Era Governance. Journal of Public Administration Research and Theory. 16, 3 (2006), 467-494.

[13] Dunleavy, P., Margetts, H., Bastow, S. and Tinkler, J. 2006. The Theory of Modern Bureaucracy and the Neglected Role of IT. Digital era governance: IT corporations, the state, and e-government. Oxford University Press.

[14] Eubanks, V. 2017. Automating inequality: how high-tech tools profile, police, and punish the poor. St. Martin's Press.

[15] Frey, B.S. and Jegen, R. 2001. Motivation Crowding Theory. Journal of Economic Surveys. 15, 5 (Dec. 2001), 589-611. DOI:https://doi.org/10.1111/1467-6419.00150.

[16] Gasser, U. and Palfrey, J. 2007. Breaking Down Digital Barriers: How and When ICT Interoperability Drives Innovation. (2007).

[17] Gil-Garcia, J.R., Chengalur-Smith, I. and Duchessi, P. 2007. Collaborative eGovernment: impediments and benefits of information-sharing projects in the public sector. European Journal of Information Systems. 16, 2 (Apr. 2007), 121133. DOI:https://doi.org/10.1057/palgrave.ejis.3000673.

[18] Gil-Garcia, J.R. and Sayogo, D.S. 2016. Government inter-organizational information sharing initiatives: Understanding the main determinants of success. Government Information Quarterly. 33, 3 (Jul. 2016), 572-582. DOI:https://doi.org/10.1016/j.giq.2016.01.006.

[19] Gottschalk, P. 2009. Maturity levels for interoperability in digital government. Government Information Quarterly. 26, 1 (Jan. 2009), 75-81. DOI:https://doi.org/10.1016/j.giq.2008.03.003.

[20] Henning, F. 2018. A theoretical framework on the determinants of organisational adoption of interoperability standards in Government Information Networks. Government Information Quarterly. 35, 4, Supplement (Oct. 2018), S61-S67. DOI:https://doi.org/10.1016/j.giq.2015.11.008

[21] Hood, C. 2006. Gaming in Targetworld: The Targets Approach to Managing British Public Services. Public Administration Review. 66, 4 (Jul. 2006), 515521. DOI:https://doi.org/10.1111/j.1540-6210.2006.00612.x.

[22] Hood, C. 1995. The "New Public Management" in the 1980s: variations on a theme. Accounting, Organizations and Society. 20, 2 (1995), 93.

[23] Janssen, M. and Kuk, G. 2016. The challenges and limits of big data algorithms in technocratic governance. Government Information Quarterly. 33, 3 (Jul. 2016), 371-377. DOI:https://doi.org/10.1016/j.giq.2016.08.011.

[24] Karlsson, F., Frostenson, M., Prenkert, F., Kolkowska, E. and Helin, S. 2017. Inter-organisational information sharing in the public sector: A longitudinal case study on the reshaping of success factors. Government Information Quarterly. 34, 4 (Dec. 2017), 567-577. DOI:https://doi.org/10.1016/j.giq.2017.10.007.

[25] Kehl, D.L., Kessler, S.A. and Guo, P. 2017. Algorithms in the Criminal Justice System: Assessing the Use of Risk Assessments in Sentencing. Responsive Communities Initiative, Berkman Klein Center for Internet \& Society, Harvard Law School. (2017).

[26] Landsbergen Jr., D. and Wolken Jr., G. 2001. Realizing the Promise: Government Information Systems and the Fourth Generation of Information Technology. Public Administration Review. 61, 2 (Apr. 2001), 206-220.

[27] Lindblom, C.E. 1979. Still muddling, not yet through. Public administration review. 39, 6 (1979), 517-526.

[28] Lindblom, C.E. 1959. The Science of "Muddling Through." Public

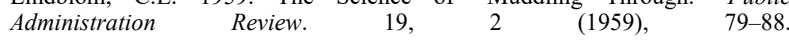
DOI:https://doi.org/10.2307/973677.
[29] Liptak, A. 2017. Sent to Prison by a Software Program's Secret Algorithms. The New York Times.

[30] Machine Bias: 2016. https://www.propublica.org/article/machine-bias-riskassessments-in-criminal-sentencing. Accessed: 2019-01-27.

[31] Malomo, F. and Sena, V. 2017. Data Intelligence for Local Government? Assessing the Benefits and Barriers to Use of Big Data in the Public Sector Policy \& Internet. 9, 1 (Mar. 2017), 7-27. DOI:https://doi.org/10.1002/poi3.141.

[32] Margetts, H. and Dunleavy, P. 2013. The second wave of digital-era governance: a quasi-paradigm for government on the Web. Philosophical Transactions of the Royal Society A: Mathematical, Physical and Engineering Sciences. 371, 1987 (Feb. 2013). DOI:https://doi.org/10.1098/rsta.2012.0382.

[33] McLoughlin, I., Wilson, R. and Martin, M. 2013. Digital government at work: a social informatics perspective. Oxford University Press.

[34] Mittelstadt, B.D., Allo, P., Taddeo, M., Wachter, S. and Floridi, L. 2016. The ethics of algorithms: Mapping the debate. Big Data \& Society. 3, 2 (Dec. 2016), 2053951716679679. DOI:https://doi.org/10.1177/2053951716679679.

[35] Oswald, M., Urwin, S., Barnes, G.C. and Grace, J. 2018. Algorithmic risk assessment policing models: lessons from the Durham HART model and 'Experimental' proportionality. Information \& Communications Technology Law. 27, 2 (May 2018), 223-250. DOI:https://doi.org/10.1080/13600834.2018.1458455.

[36] Peeters, R. and Widlak, A. 2018. The digital cage: Administrative exclusion through information architecture - The case of the Dutch civil registry's master data management system. Government Information Quarterly. 35, 2 (Apr. 2018), 175-183. DOI:https://doi.org/10.1016/j.giq.2018.02.003.

[37] Public Service Transformation Academy 2018. Public service: state of transformation. Public Service Transformation Academy.

[38] Reddick, C.G. 2004. Assessing Local Government Revenue Forecasting Techniques. International Journal of Public Administration. 27, 8-9 (Jul. 2004), 597-613. DOI:https://doi.org/10.1081/PAD-120030257.

[39] Sanders, M., Lawrence, J., Gibbons, D. and Calcraft, P. 2017. Using Data Science in Policy. Behavioural Insights Team.

[40] Simon, H.A. 1991. Bounded Rationality and Organizational Learning. Organization Science. 2, 1 (Feb. 1991), 125-134.

[41] Simon, H.A. 1972. Theories of bounded rationality. Decision and organization C.B. McGuire and R. Radner, eds. North-Holland Pub. Co. 161-176.

[42] Symons, T. 2016. Wise Council: Insights from the Cutting Edge of Data-Driven Local Government. Nesta.

[43] Taylor, S. 2018. BBC Daily Politics Show 23rd April Alexa Full Version.

[44] Voigt, C. and Bright, J.M. 2016. The lightweight smart city and biases in repurposed big data. (2016)

[45] Wachter, S. and Mittelstadt, B. 2018. A Right to Reasonable Inferences: Re Thinking Data Protection Law in the Age of Big Data and AI. Technical Report \#ID 3248829. Social Science Research Network.

[46] Wang, F. 2018. Understanding the dynamic mechanism of interagency government data sharing. Government Information Quarterly. 35, 4 (Oct. 2018), 536-546. DOI:https://doi.org/10.1016/j.giq.2018.08.003.

[47] Weber, M. 1968. Economy and society: an outline of interpretive sociology. Bedminster Press.

[48] Weber, M. 2013. The Protestant ethic and the spirit of capitalism. Routledge.

[49] Winners of the 2016 Digital Leaders 100 Awards announced: https://www.computerweekly.com/news/450298528/Winners-of-the-2016Digital-Leaders-100-Awards-announced. Accessed: 2019-01-27.

[50] Yang, T.-M. and Maxwell, T.A. 2011. Information-sharing in public organizations: A literature review of interpersonal, intra-organizational and interorganizational success factors. Government Information Quarterly. 28, 2 (Apr. 2011), 164-175. DOI:https://doi.org/10.1016/j.giq.2010.06.008.

[51] Yang, T.-M., Pardo, T. and Wu, Y.-J. 2014. How is information shared across the boundaries of government agencies? An e-Government case study. Government Information Quarterly. 31, 4 (Oct. 2014), 637-652. DOI:https://doi.org/10.1016/j.giq.2014.05.002.

[52] Zinszer, K., Tamblyn, R., Bates, D.W. and Buckeridge, D.L. 2013. A qualitative study of health information technology in the Canadian public health system. BMC Public Health. (2013). DOI:https://doi.org/10.1186/1471-2458-13-509. 